\title{
Design and Characterization of a Centrifugal Compressor Surge Test Rig
}

\author{
Kin Tien Lim, Se Young Yoon, Christopher P. Goyne, Zongli Lin, and Paul E. Allaire \\ Department of Mechanical and Aerospace Engineering, University of Virginia, Charlottesville, VA 22904, USA \\ Correspondence should be addressed to Christopher P. Goyne, goyne@virginia.edu \\ Received 23 September 2010; Accepted 12 April 2011 \\ Academic Editor: Hyeong Joon Ahn \\ Copyright () 2011 Kin Tien Lim et al. This is an open access article distributed under the Creative Commons Attribution License, \\ which permits unrestricted use, distribution, and reproduction in any medium, provided the original work is properly cited.
}

A detailed description of a new centrifugal compressor surge test rig is presented. The objective of the design and development of the rig is to study the surge phenomenon in centrifugal compression systems and to investigate a novel method of surge control by active magnetic bearing servo actuation of the impeller axial tip clearance. In this paper, we focus on the design, initial setup, and testing of the rig. The latter two include the commissioning of the rig and the experimental characterization of the compressor performance. The behavior of the compressor during surge is analyzed by driving the experimental setup into surge. Two fundamental frequencies, $21 \mathrm{~Hz}$ and $7 \mathrm{~Hz}$, connected to the surge oscillation in the test rig are identified, and the observed instability is categorized according to the intensity of pressure fluctuations. Based on the test results, the excited pressure waves are clearly the result of surge and not stall. Also, they exhibit the characteristics of mild and classic surge instead of deep surge. Finally, the change in the compressor performance due to variation in the impeller tip clearance is experimentally examined, and the results support the potential of the tip clearance modulation for the control of compressor surge. This is the first such demonstration of the feasibility of surge control of a compressor using active magnetic bearings.

\section{Introduction}

Surge is an instability phenomenon that is known to occur in centrifugal compressors under low flow conditions. The highly dynamic nature of the phenomenon limits the safe operating region and, hence, the available performance of these machines. At reduced flow rates, the pressure buildup in the compression system reaches a critical point, where the flow characteristics approach a limit cycle. This can be very destructive as reversal of flow could occur in the compressor. Such changes result in sudden thrust load reversal and also high gas temperatures due to the recycling of the compressed gas. These are damaging to both the compressor and its components. A detailed review of the surge instability can be found in [1].

A widely adopted industrial practice to protect equipment from surge is to avoid operating the compressor in unstable regions by keeping a safety margin within its operating envelop [2]. The surge margin is usually about $10 \%$ of the flow rate away from surge. This "surge avoidance" practice limits the useful operating envelop of the compressor and can result in the compressor operating at lower efficiency [3]. A more advanced option involves surge suppression, which relies on accurate system models to develop surge control strategies. Such strategies stabilize the compression system to enable operation in the unstable region. A brief review of the recent literature in active and passive surge control is presented in [4].

An innovative method to control surge, using Active Magnetic Bearings (AMBs) to axially actuate the impeller tip clearance, has been studied over the years in the Rotating Machinery and Controls (ROMAC) Laboratory. Promising simulation results have been obtained by Sanadgol [5]. Sanadgol's results predicted that axial modulation of the impeller tip clearance could stabilize surge during the actuation. This would potentially allow magnetic bearings to serve not only as active suspension bearings for compressors but also as a dynamic actuator to stabilize compressor surge. An operational compressor test rig is required to validate this theory and the simulation results. This test rig has been mechanically designed and commissioned, and the results of this work are presented here.

Various test rigs are presented in the literature for the research of different methods of surge control [4, 6-9]. Although some of them provide a good platform for the 
study of surge control applicable for industrial compressors, the majority of them are based on small low-throughput compressors, and the applicability of the results obtained from these small turbo machines to larger industrial-sized systems is still a topic of much discussion. Thus, researchers are forced to work with this tradeoff between cost and benefit that comes with the dimension of the experimental test rig for the study of compressor instabilities.

With this in mind, a new centrifugal compressor surge test rig has been designed and commissioned as part of the present work. The test rig is an industrial-sized high-speed centrifugal compressor that is fully supported on magnetic bearings, both radially and axially. The specific objectives of this work are to

(1) design and commission the compressor test rig and determine the performance of the compressor over the safe operating envelop,

(2) evaluate the performance of the compressor and experimentally characterize operation in its surge instability region so as to aid future development and implementation of a surge controller,

(3) experimentally demonstrate the ability to influence the performance of the compressor through modification of the impeller tip clearance via active magnetic bearing actuation.

The paper first presents details of the test rig and experiment design. The results of the commissioning and characterization of the compressor are then presented. The performance of the compressor is characterized at various speeds of operation, the compressor characteristic map is obtained based on collected data, and the safe operating envelope of the test rig is experimentally determined. Next, the compressor instability, commonly known as surge, is experimentally demonstrated on the test rig. The characteristics of surge are identified for the test rig by examining pressure fluctuations. Finally, the effect of the impeller tip clearance on the compressor output is measured in order to test the feasibility of the proposed surge control method that was examined in [5]. A significant issue is the determination of whether the pressure waves in the discharge plenum are associated with surge or stall. By comparison of the wave characteristics with known stall and surge characteristics for centrifugal compressors, the nature of the disturbances is evaluated. Finally, we offer a discussion of the observed data, and we conclude the paper with comments on the future work.

The contribution of the present paper is twofold. First, the design, characterization, and commissioning of a new compressor test rig that is now available for industrial surge testing is presented. Second, for the first time, the paper documents experimental evidence of the feasibility of compressor surge control using active magnetic bearing actuation of the impellor tip clearance.

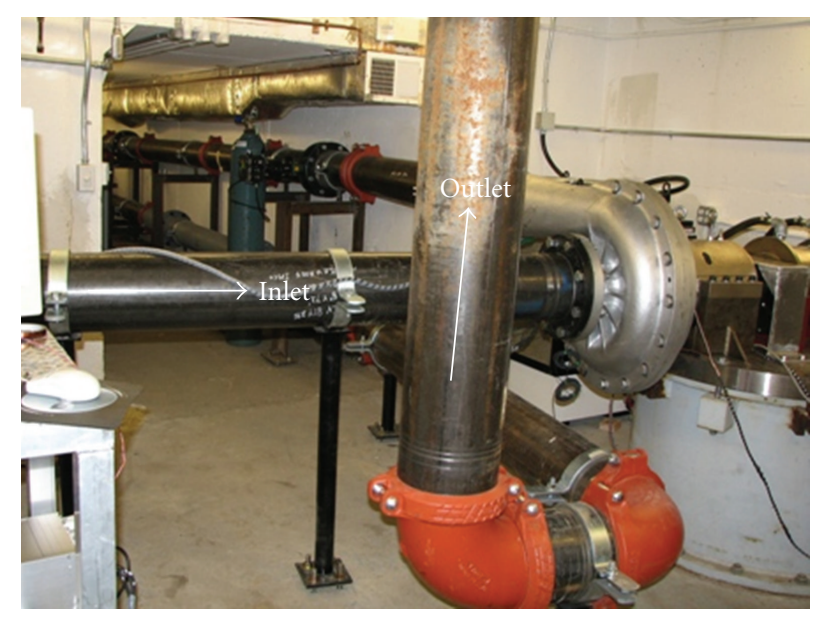

FIgURE 1: Photograph of the compressor test rig.

\section{Test Rig Description}

Figure 1 shows a photograph of the test rig, with the direction of the inlet and outlet flow, and Figure 2 shows the layout of the experimental setup. The compressor surge test rig mainly consists of three sections. These are the driver, the driven equipment, and the supporting system such as the piping and motor accessories. The driver is a high-speed induction motor that is controlled by a variable frequency drive. The compressor was directly coupled to the motor. The compressor is a single stage type with an overhung semiopen impeller, and is fully supported on active magnetic bearings, both radially and axially. The compressor service is atmospheric air, and, due to the unique test location of the test rig, an inlet filter was installed in the inlet piping to take in clean air from the atmosphere. In addition, in order to install an orifice flow meter and also allow varying locations for the throttle valve as shown in Figure 2, the piping was assembled using Victaulic couplings to provide flexibility of installation.

The test rig has been developed and designed to allow actual industrial compressor surge testing. Major components of this rig were supplied by ROMAC Laboratory members, such as the single stage overhung centrifugal compressor by Kobe Steel, the magnetic bearings by Revolve, and the motor rotor by SKF. In order to produce a functioning, practical test rig, design work included the work of [10], as well as bearing selection for the motor, a modal analysis for the piping supports, rotordynamics analysis of the compressor rotor assembly, and the selection of accessory components such as the motor chiller and the orifice flow meter.

The drive motor is an induction type that is rated for $125 \mathrm{~kW}$ at $30,000 \mathrm{rpm}$. It was driven by a variable frequency drive produced by Alcomel. The motor was specified with more than sufficient power to drive the test rig over its entire operating range and up to a maximum design speed of $23,000 \mathrm{rpm}$. As per the compressor supplier Kobe, the compressor was estimated to only require $52 \mathrm{~kW}$ of power at its maximum speed. Details of the motor design can be 


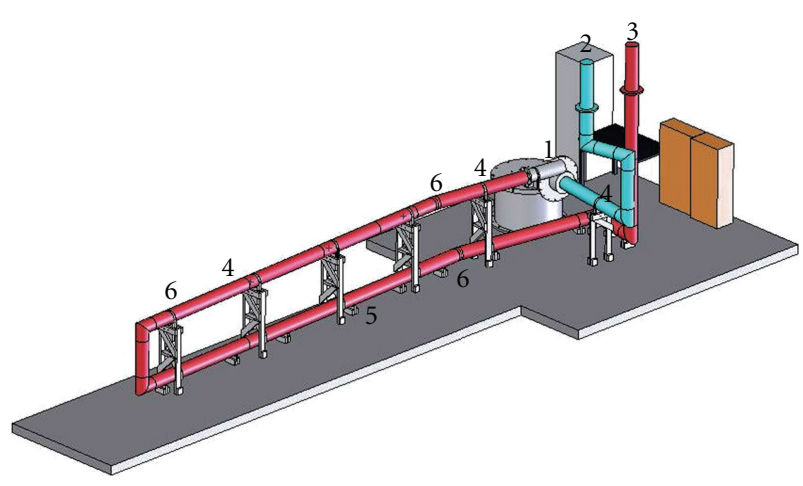

1-Compressor

3-Exhaust piping

5-Orifice flow meter
2-Inlet piping

4-Pressure transducers and thermocouples 6-Throttle valve positions

Figure 2: Layout of the experimental setup. Possible throttle valve locations are at $2.2 \mathrm{~m}, 7.1 \mathrm{~m}$, and $15 \mathrm{~m}$ along the exhaust piping measured from the compressor.

found in [10]. The coupling selected to connect the motor shaft and the compressors was a Thomas flexible disk-pack coupling. This coupling allows a margin for both axial and radial misalignment between the motor and the test sections. The coupling was balanced and was rated for the maximum design speed of 23,000 rpm [10].

The compressor section consists of the compressor and the support for the rotating components. The compressor rotor is supported by two radial magnetic bearings and one thrust bearing. Figure 3 shows the compressor section, and Figure 4 shows the cross-sectional drawing of the compressor test rig. Position measurements are very critical for active magnetic bearings as the measurements provide the position feedback to the bearing controllers to ensure the stability of the bearings and the optimum reference position of the rotor. The two radial bearings use reluctance sensors to provide accurate position measurements of the compressor rotor. The axial position is measured with two SKF $5 \mathrm{~mm}$ button eddy current probes. One probe is placed on either side of the thrust bearing and targets a shoulder on the compressor rotor to measure the axial position of the rotor for the controller. An exploded view of the compressor section, with the bearing placement, is given in Figure 5.

The active magnetic thrust bearing controls the axial position of the shaft up to a maximum end-to-end displacement of $0.5 \mathrm{~mm}$. The thrust bearing is composed of two electromagnetic actuators acting on opposite sides of a thrust disk on the rotor. These work in a differential mode to create a stabilizing force in the axial direction with an appropriate position feedback controller. The axial displacement of the shaft and the attached impeller can also be servo controlled by changing the reference set point in the stabilizing feedback loop of the magnetic bearings. Therefore, it is possible to move the compressor rotor forward using the thrust magnetic bearing and decrease the axial clearance between the impeller tip and the static shroud, or to move the rotor backward in order to increase the impeller tip clearance.

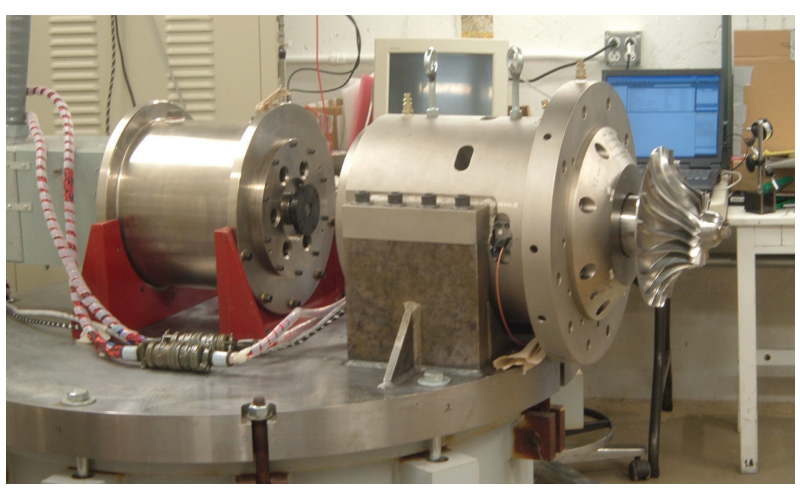

FIGURE 3: Induction motor and compressor without front volute.

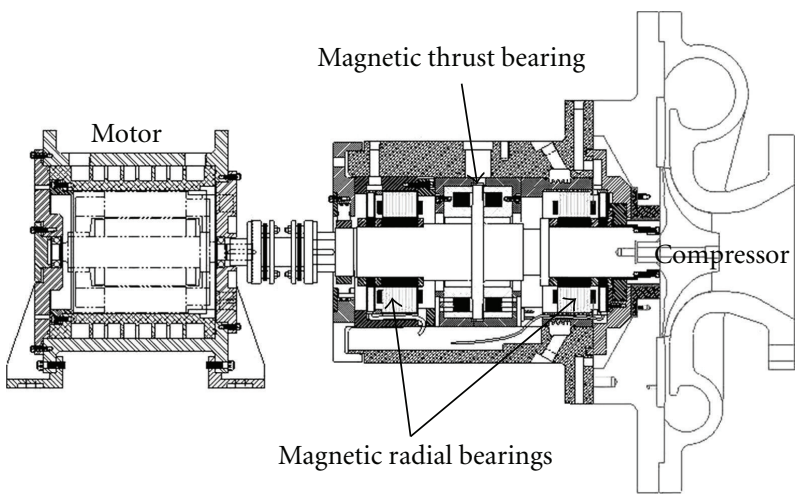

FIgURE 4: Cross-sectional drawing of test rig.

Modulation of the impeller clearance can be static, as for the study here, or can be dynamically controlled.

The compressor is overhung in design and only has a single stage. Its impeller is unshrouded, and it can be used with either a vane or vaneless diffuser. For the current tests, it was set up with a vaneless diffuser. The compressor is rated to provide a maximum flow rate of $2,500 \mathrm{~m}^{3} / \mathrm{hr}$ and develops a pressure ratio of 1.7. In addition to the pressure, flow rate, and temperature measurements along the inlet and exhaust piping of the test rig, there are twelve high-bandwidth Kulite pressure transducers mounted on the compressor front housing, as shown in Figure 6. The sensors measured the time-resolved pressure distribution in the impeller and the diffuser regions inside the compressor casing and provided data aimed at providing a deeper insight into the dynamics of the compressor and the transients of surge. Figure 7 presents an example of the measured time-averaged pressure distribution inside the compressor casing for the compressor operating at $16,290 \mathrm{rpm}$. This arrangement of sensors enables the visualization of surge or stall effects inside the compressor front casing.

The major data acquisition was performed using LabVIEW software. High-speed data acquisition cards, PXI-6052 and PXI-6071, were used together with National Instruments (NI) signal processing cards. 


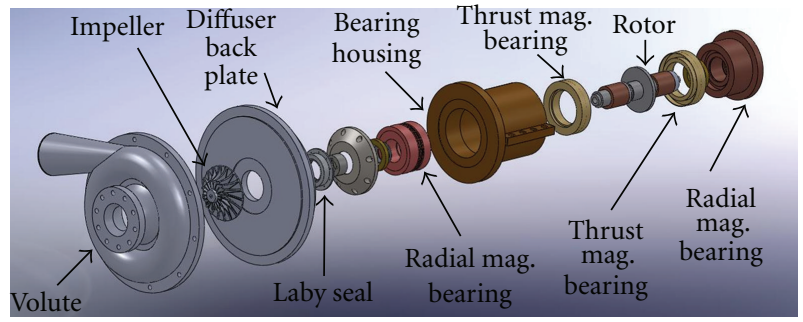

FIGURE 5: Exploded view of the compressor and magnetic bearing assembly.

\section{Experimental Results}

Experiments were first conducted to commission the test rig and measure the performance of the compressor over the safe operating envelope, up to the onset of surge. The operating pressures of the compressor were then experimentally characterized in order to assess operation in the surge instability region. Finally, the influence on compressor performance of active magnetic bearing actuation of the impeller tip clearance was examined.

For initial testing, the throttle valve was located on the closest location to the compressor, as show in Figure 2. This was done to minimize pressure fluctuations and prevent damage due to the intensity of the surge oscillation. The discharge throttle valve was slowly closed while the compressor was running at a constant speed. The instability point encountered was analyzed to determine the type of instability observed, whether it could be characterized as a mild surge, classic surge, deep surge, modified surge, or even stall, as defined in [11]. Such an analysis provided a better understanding of the characteristics of the instability of the test rig and served as a reference when examining the time resolved pressure measurements. The pressure histories were measured in the inlet, inside the compressor casing and in the discharge plenum, as the throttle valve was closed. Pressure and flow data were recorded through the detection of an audible sound change or low-frequency sound. The throttle valve was closed further beyond the first detection of the low-frequency sound. This was mainly to experimentally investigate if the unstable behavior would change and what the change may be. Finally, the instability test was repeated at different speeds to verify if they were speed dependent or not.

Figure 8 shows the multispeed characteristic curve of this test rig. The mass flow and pressure relationship for the range of speeds is as would be expected for this type of compressor, and this confirms that the test rig is representative of an industrial centrifugal compressor. The region of the observed audible sound change, and the onset of surge, is marked as a region bounded by the solid (blue) curves on the left-hand side of the figure.

Figures 9, 10, and 11 present examples of the time resolved pressure measured in the discharge plenum, inside the compressor casing, and in the inlet of the compressor, all as the throttle valve was closed. As is evident in each figure, when the throttle valve was closed, the pressure started to fluctuate. This point is marked by the vertical

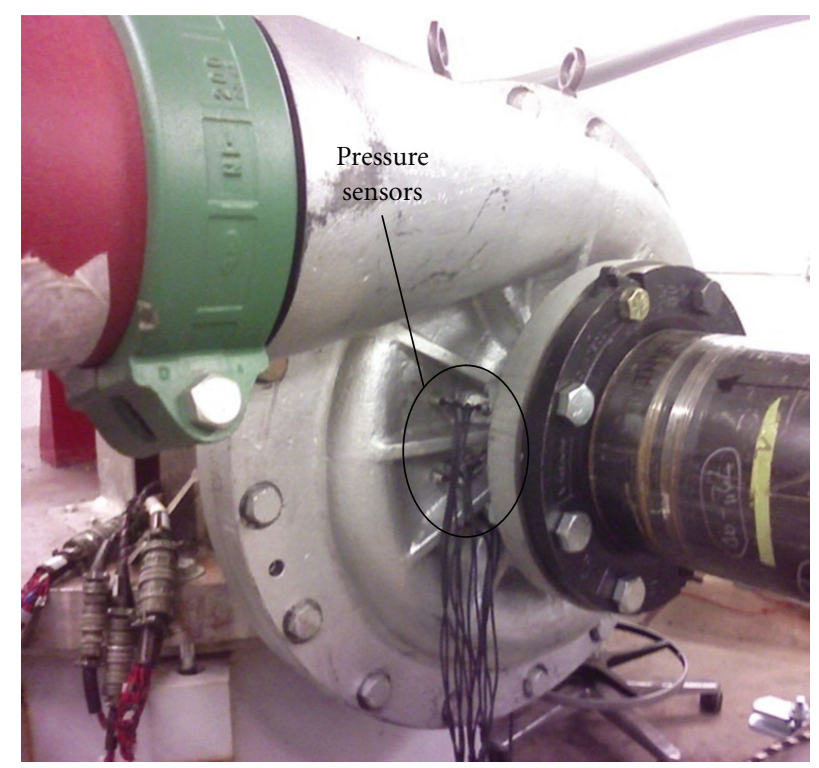

(a)

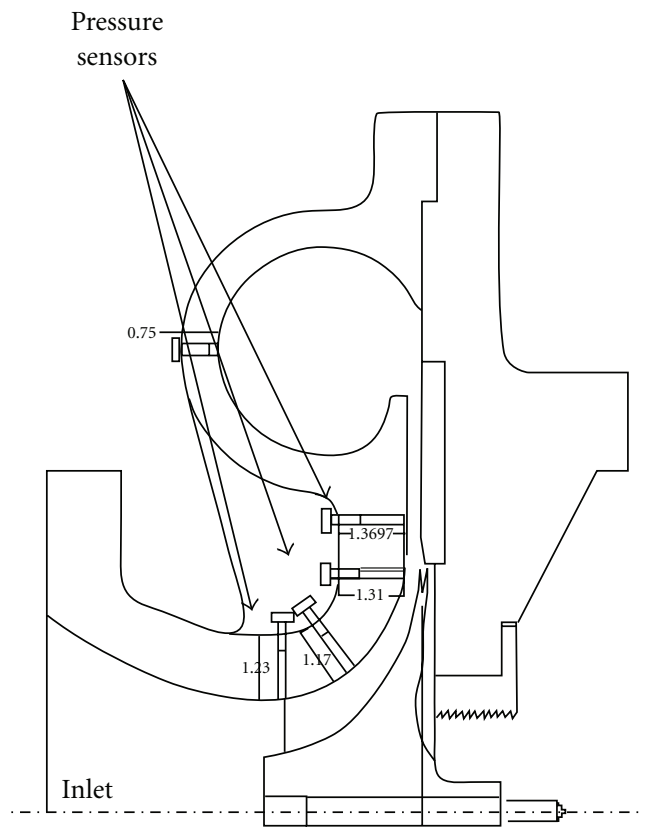

(b)

Figure 6: Twelve pressures sensors, divided into three lines of four, installed on the compressor front casing. Relative locations are shown in Figure 7.

(red) dashed line. An audible low-frequency sound could also be heard distinctly from the compressor at this point. In addition, the pressure in all three locations started to fluctuate with a frequency of approximately $21 \mathrm{~Hz}$. In this case, this corresponded to $28 \%$ valve open position. When the throttle valve is closed further to $27 \%$ and even $26 \%$, the pressure frequency started to change to a dominant $7 \mathrm{~Hz}$, and noticeably higher pressure amplitude fluctuations were observed. These higher pressures were particularly noticeable in the discharge plenum. The changes in frequency were observed in all three locations on the compressor test rig. 


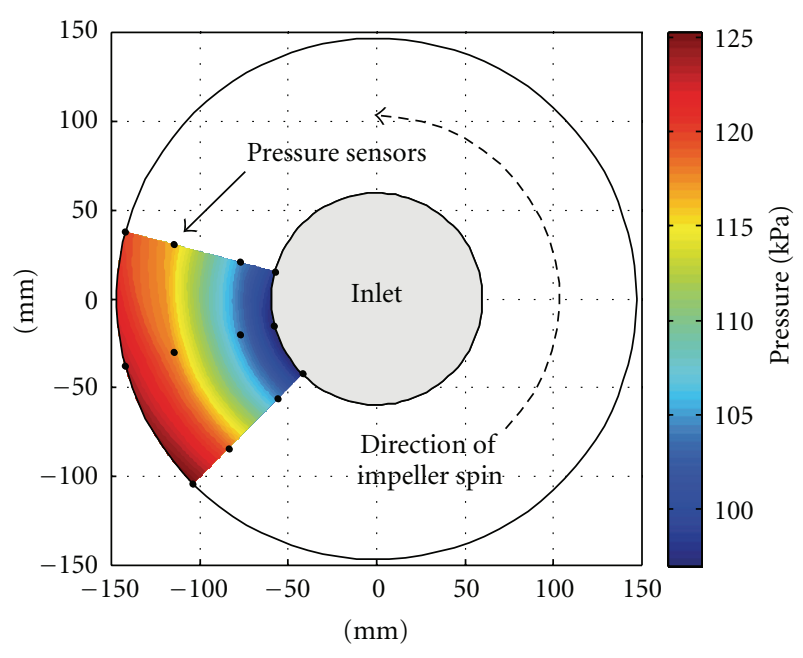

FIGURE 7: Experimental pressure map of the impeller region inside the compressor front casing, for the compressor operating at $16,290 \mathrm{rpm}$ and $34 \%$ throttle valve opening. The measurement points of the twelve pressure transducers are marked by the dots in the map.

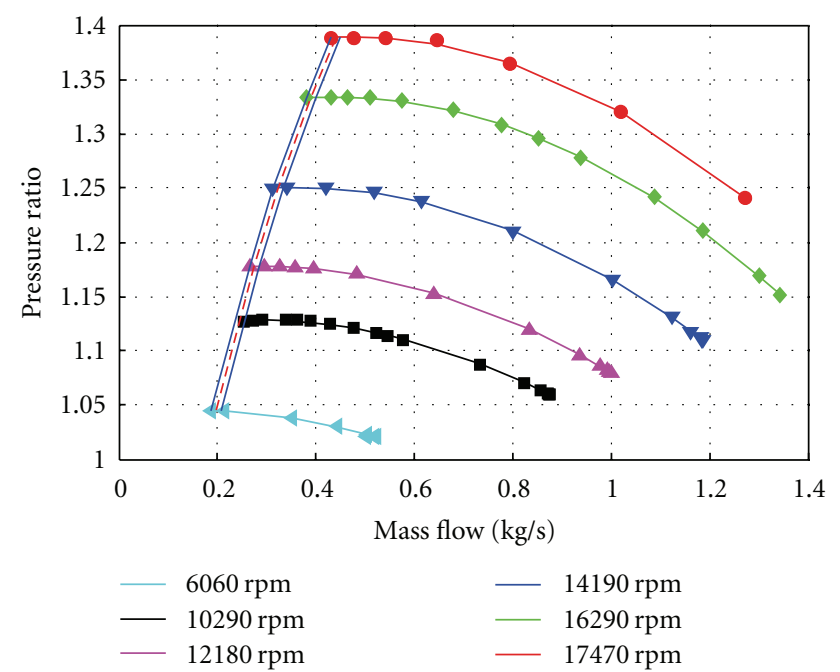

FIgURE 8: Multispeed characteristic curves of test rig $(0.6 \mathrm{~mm}$ $(23$ mils $)$ tip clearance, inlet pressure $=1.012$ bar, inlet temp. $=22 \mathrm{C}$, humidity $=24 \%$ ).

Figures 12, 13, and 14 are the water fall plots for the exhaust location and show the discharge pressure, frequency, and flow rate on the same plot to illustrate the change in frequency as the throttle valve is closed. Experimental tests were carried out at three different speeds to evaluate the effect on speed change on the observed dominant frequencies. Figure 12 shows the results at 10,000 rpm, Figure 13 shows the results at $15,000 \mathrm{rpm}$, and Figure 14 shows the waterfall plot results at $16,000 \mathrm{rpm}$. The point at which the audible sound occurred is also indicated in the figure. It can be observed from the plots that the sound heard corresponded to the start of the $21 \mathrm{~Hz}$ frequency component. As the throttle valve was closed further, the dominant frequency of the pressure oscillations shifted to $7 \mathrm{~Hz}$. This occurred for all

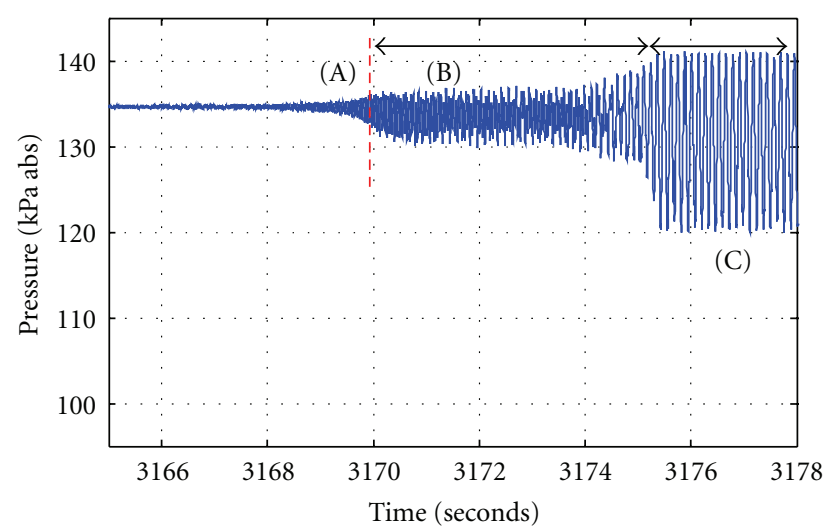

Figure 9: Pressure fluctuations in the discharge plenum during the onset of surge at $16,000 \mathrm{rpm}$ : (A) instability initiationobserved audible sound change, (B) initial pressure fluctuations at a frequency near $21 \mathrm{~Hz}$, and (C) pressure fluctuations changed to a lower frequency near $7 \mathrm{~Hz}$ as throttle valve closed further.

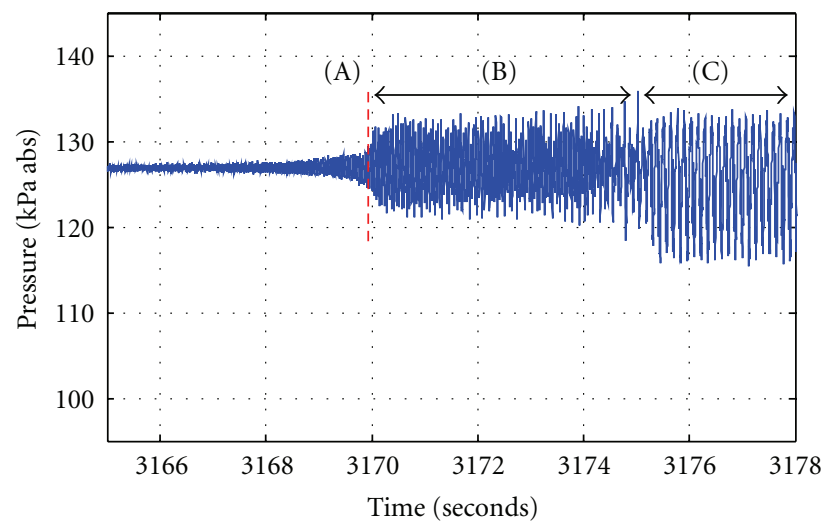

Figure 10: Pressure fluctuations in the compressor during the onset of surge at 16,000 rpm: (A) instability initiation-observed audible sound change, (B) initial pressure fluctuations at a frequency near $21 \mathrm{~Hz}$, and (C) pressure fluctuations changed to a lower frequency near $7 \mathrm{~Hz}$ as throttle valve closed further.

three speeds. This comparison shows that the dominant frequency was not related to speed. It appeared to be occurring repetitively at almost the same frequency at different speeds of operation. As is discussed further below, this comparison supported the finding that the detected dominant frequencies of $21 \mathrm{~Hz}$ and $7 \mathrm{~Hz}$ were related to some form of inherent surge frequencies within the test rig.

In order to examine the pressure transients in more detail, Figure 15 shows the pressure in the compressor discharge plenum plotted over a 1-second period at a throttle valve opening of $28 \%$. The pressure is sinusoidal, and the $21 \mathrm{~Hz}$ component of the signal is clearly evident. Similar results were obtained as the throttle valve was closed further to an opening of $26 \%$, as seen in Figure 16 . However, the pressure profile changed to a lower frequency of $7 \mathrm{~Hz}$ and the oscillations became more sinusoidal.

As discussed above, once the safe operating envelope and the instability region were explored, experiments were performed to examine the influence of active magnetic 


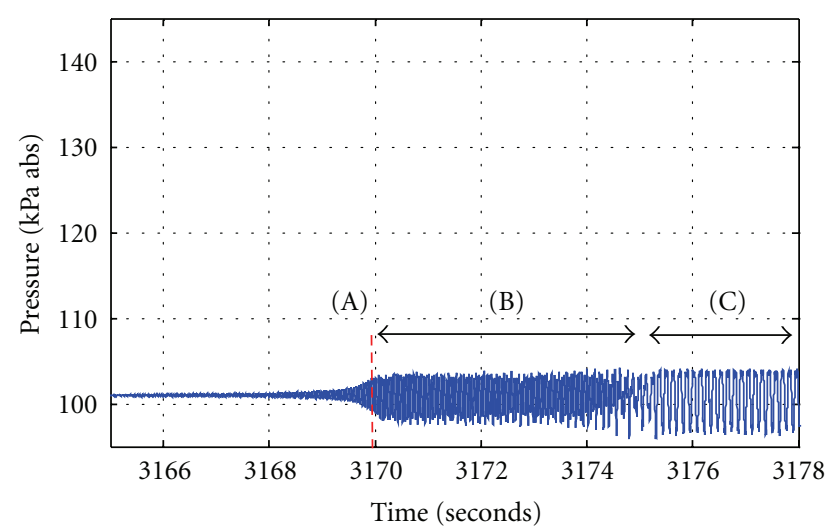

Figure 11: Pressure fluctuations in the inlet during the onset of surge at 16,000 rpm: (A) instability initiation-observed audible sound change, (B) initial pressure fluctuations at a frequency near $21 \mathrm{~Hz}$, and (C) pressure fluctuations changed to a lower frequency near $7 \mathrm{~Hz}$ as throttle valve closed further.

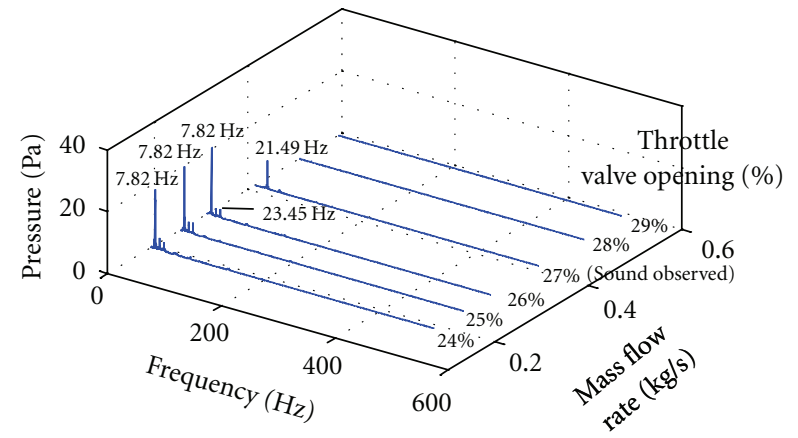

Figure 12: Waterfall plot of the exhaust (discharge plenum) pressure at $10,000 \mathrm{rpm}$.

bearing actuation of the impeller tip clearance on compressor performance. In order to demonstrate the feasibility of future active surge control and maximize safety, only static actuation of the impeller tip clearance was attempted for this study. The steady-state performance of the compressor at different values of the impeller tip clearance was, therefore, investigated. Figure 17 shows the measured characteristic curves at different impeller tip clearance values for the compressor operating at $16,287 \mathrm{rpm}$. The same test was repeated at $14,900 \mathrm{rpm}$, and the resulting characteristic curves are shown in Figure 18. From this impeller tip clearance test, it can be seen that the active magnetic bearings have the capability to change the compressor characteristics. Further, the results show that this capability exists at multiple speeds. These results are discussed further in the following section.

\section{Discussion}

The $21 \mathrm{~Hz}$ frequency observed in the initiation of surge for all three different speeds occurred with a distinct audible low-frequency sound. The observed $21 \mathrm{~Hz}$ was found to be near the Helmholtz resonance frequency that was calculated for this compression system. The Helmholtz frequency was estimated to be between $10.5 \mathrm{~Hz}$ and $19.2 \mathrm{~Hz}$ (for the smallest

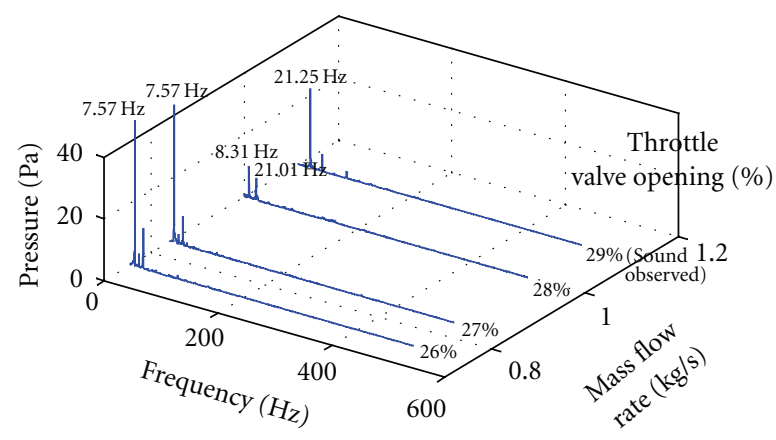

FIGURE 13: Waterfall plot of the exhaust (discharge plenum) pressure at $15,000 \mathrm{rpm}$.

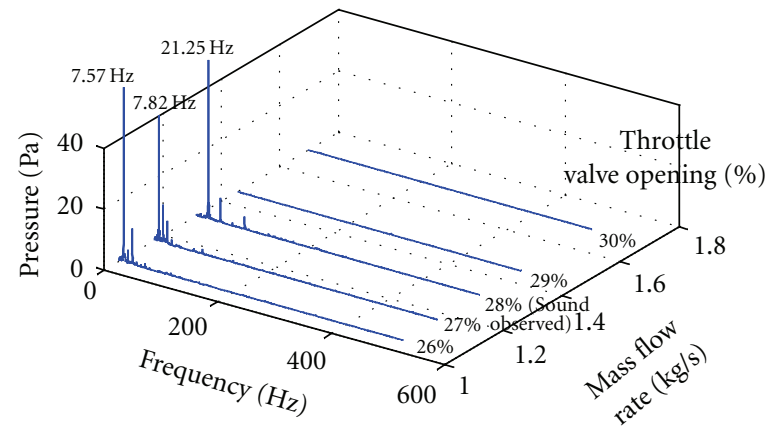

FIGURE 14: Waterfall plot of the exhaust (discharge plenum) pressure at $16,000 \mathrm{rpm}$.

discharge plenum configurations at which the testing was done). The three observations on sound, pressure fluctuations, and Helmholtz frequency strongly suggested that the $21 \mathrm{~Hz}$ was what is commonly known as mild surge [12]. The $21 \mathrm{~Hz}$ oscillation appearance always occurred with a sound change from the compressor, even at different operating speeds. This indicates that it was not a stall phenomenon because stall would typically be related to speed [13]. And, if stall cells were formed, it would typically require the flow in the compression system flow to be increased significantly in order to flush or wash out the stall cells in the impeller and diffuser section. In [13], it was found that the compression system could require a complete shutdown in order to eliminate the stall cells formed. In this test rig, the surge instability connected to the $21 \mathrm{~Hz}$ frequency component would immediately disappear when the throttle valve was reopened slightly to allow a small increase in flow through the compression system. Thus, these observations did not support that the $21 \mathrm{~Hz}$ was a stall phenomena and it confirmed that it was actually mild surge. It was expected that this mild surge would not result in reversal of flow in the compression system [14].

The observed shifting of the surge oscillation frequency from $21 \mathrm{~Hz}$ to $7 \mathrm{~Hz}$ as the throttle valve was closed further seemed to indicate a change in the instability phenomena. As outlined in much of the literature, there are typical characteristics known as deep surge, classic surge, and mild surge. Though at $7 \mathrm{~Hz}$, the amplitude of the pressure fluctuation seemed much larger compared to the $21 \mathrm{~Hz}$ 


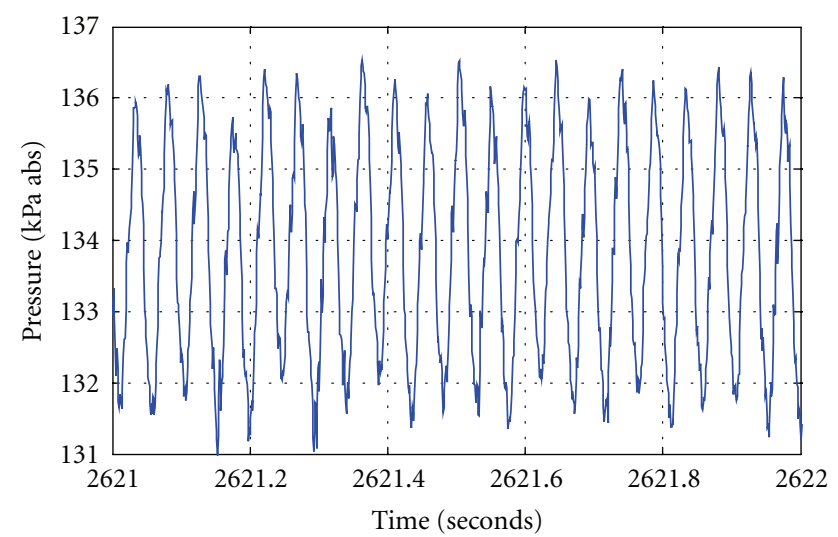

Figure 15: Pressure fluctuations in the exhaust (discharge plenum) prior to audible change at $16,000 \mathrm{rpm}$.

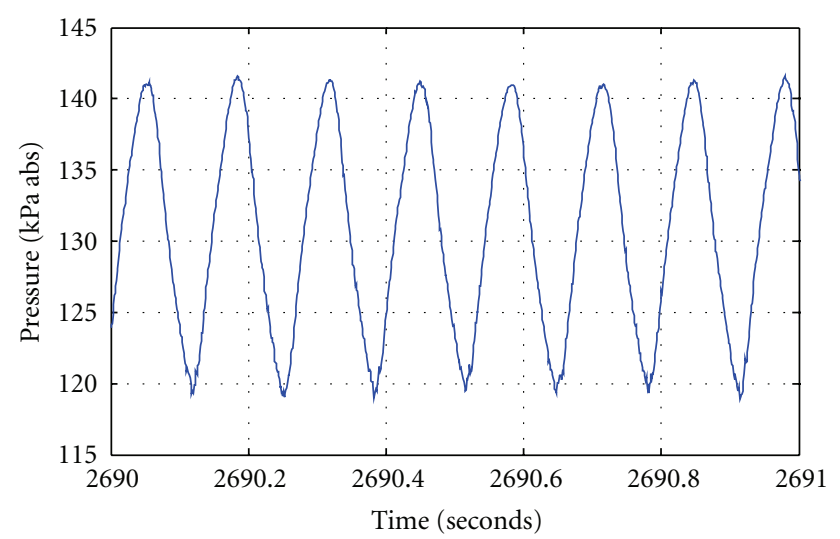

FIGURE 16: Pressure fluctuations in the exhaust (discharge plenum) after audible change at $16,000 \mathrm{rpm}$.

component, it was not classified as a deep surge. This was because, if the pressure profile is observed more closely for the $7 \mathrm{~Hz}$, as shown in Figure 16, the shape of the oscillations is very close to sinusoidal and repetitive. From the literature, deep surge oscillations are characterized by a nonlinear or nonsinusoidal pressure fluctuation. Therefore, the onset of deep surge is not supported. One possible characterization of the $7 \mathrm{~Hz}$ oscillations could be what is known as a classic surge. Willems [15] found that classic surge typically occurs at frequencies between deep surge and mild surge. Classic surge is also associated with a larger pressure oscillations and no flow reversal [11].

Based on the combined evidence, it can be concluded that the $21 \mathrm{~Hz}$ is likely a resonance of the system, commonly known as a mild surge. The $7 \mathrm{~Hz}$ oscillations, which occurred with lower oscillation frequency and larger pressure amplitudes, are likely the indications of classic surge. These findings lead to the conclusion that the pressure fluctuations associated with both mild and classic surge are exhibited by the compressor test rig. Additionally, these phenomena are available for interrogation by surge control schemes that will be developed in future work as a means of avoiding surge, particularly the potentially more dangerous deep surge.

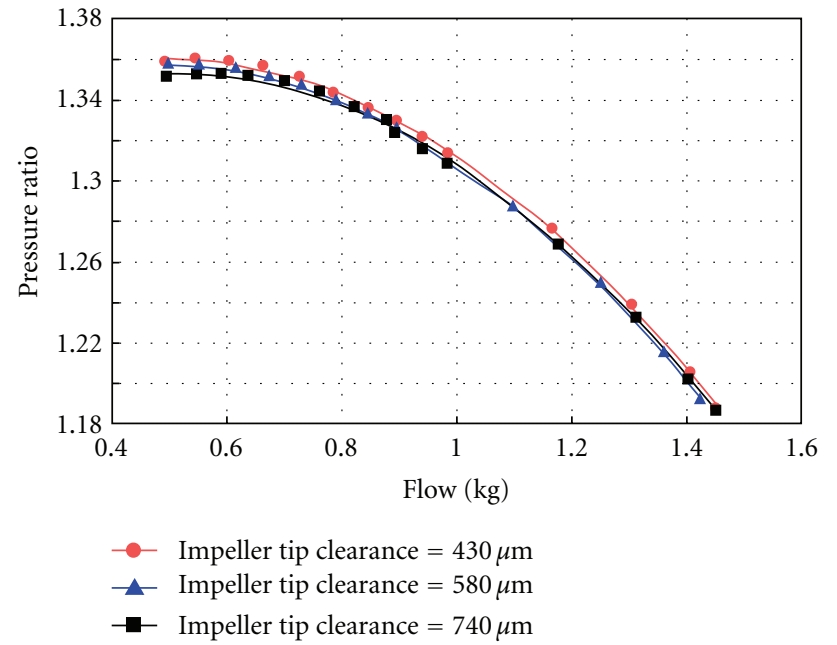

FIGURE 17: Impeller tip clearance modulation at 16,287 rpm.

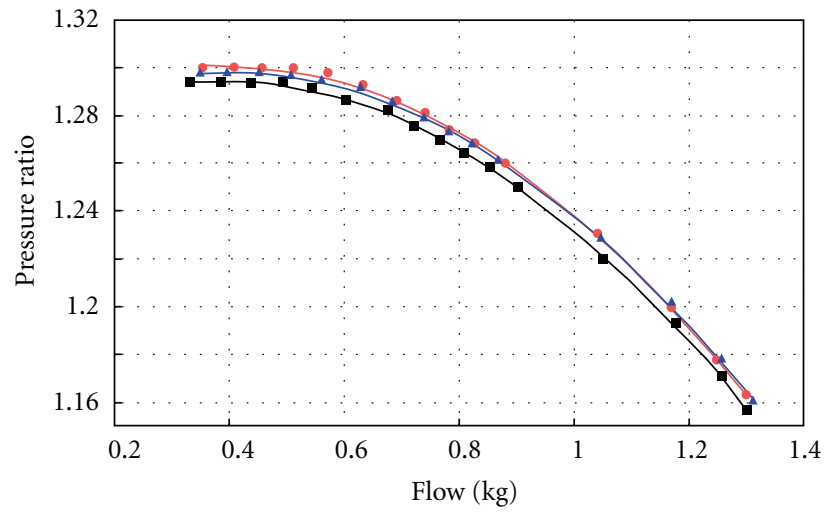

$\longrightarrow \quad$ Impeller tip clearance $=430 \mu \mathrm{m}$
$\rightarrow \quad$ Impeller tip clearance $=580 \mu \mathrm{m}$
$\rightarrow \quad$ Impeller tip clearance $=740 \mu \mathrm{m}$

FIGURE 18: Impeller tip clearance modulation at 14,900 rpm.

Therefore, the existence and identification of the mild and classic surge characteristics of the compressor support the utility of the test rig for further surge testing and control studies.

One of the most important results of this study is the ability of the active magnetic bearings to change the impeller axial tip clearance and, hence, change the compressor characteristic curve. It was observed that, for a given pressure ratio, reducing the tip clearance would increase the flow rate and increasing the clearance would decrease the flow rate. The effect is most noticeable at low flow rates. These observations are to be expected. This is because an increase or decrease of the compressor efficiency is a result of the decrease or increase, respectively, of leakage flow between the impeller and the static shroud. Further, this leakage would be expected to have a greater relative effect at low flow rates. Therefore, as is exhibited in Figures 17 and 18, the characteristic curves tend to collapse on each other at high flow rates. These trends follow those predicted by Sanadgol 
[5] and support Sanadgol's conclusion that tip clearance actuation can be used to change the characteristic curve and thus to control surge. If the compressor is operating close to the surge instability region, the tip clearance can be changed and the compressor moved to a characteristic curve that has a different surge point. The current demonstration involves only static actuation via the magnetic bearings. However, the results do experimentally demonstrate the feasibility of using dynamic actuation of the impellor tip clearance to actively control surge using magnetic bearings. A more systematic characterization of the input-output behavior from the impeller tip clearance to compressor output is necessary for the design of actual controllers. This is proposed as future work in which dynamic tip clearance actuation will be explored.

\section{Conclusion}

A high-speed centrifugal compressor test rig was successfully designed, commissioned, and characterized. The experimental setup is a first of its kind that will be used to demonstrate surge control by using magnetic bearings to servo actuate the impeller tip clearance. Details of the design of the test rig and its components were presented, and experimental measurements for the compressor operating within the stable and unstable regions were presented. Multiple surge phenomena were identified, and this supports the utility of the test rig. In addition, it was demonstrated that the test rig is able to statically modulate the impeller tip clearance, and the effect of varying the impeller tip clearance on the compressor performance was demonstrated.

The ultimate goal of the development work is to build a surge controller for the compression system and demonstrate its actual performance in experiments. The present study demonstrates the feasibility of reaching this goal. An accurate dynamic model of the compression system will be needed; however, this can be derived with measurements of both the steady state and the transient behavior such as those presented in this paper.

\section{References}

[1] E. M. Greitzer, "The stability of pumping systems-the 1980 freeman scholar lecture," Journal of Fluids Engineering, vol. 103, no. 2, pp. 193-242, 1981.

[2] G. K. McMillan, Centrifugal and Axial Compressor Control, Instrument Society of America, Research Triangle Park, NC, USA, 1983.

[3] J. T. Gravdahl and O. Egeland, Compressor Surge and Rotating Stall: Modeling and Control, Springer, London, UK, 1999.

[4] G. L. Arnulfi, P. Giannattasio, D. Micheli, and P. Pinamonti, "Extensive study on the control of centrifugal compressor surge," Proceedings of the Institution of Mechanical Engineers, Part A, vol. 220, no. 3, pp. 289-304, 2006.

[5] D. Sanadgol, Active control of surge in centrifugal compressor, Ph.D. thesis, Department of Mechanical and Aerospace Engineering, University of Virginia, Charlottesville, Va, USA, 2007.

[6] K. O. Boinov, E. A. Lomonova, A. J. A. Vandenput, and A. Tyagunov, "Surge control of the electrically driven centrifugal compressor," IEEE Transactions on Industry Applications, vol.
42, no. 6, pp. 1523-1531, 2006.

[7] D. Fontaine, S. Liao, J. Paduano, and P. V. Kokotović, "Nonlinear control experiments on an axial flow compressor," IEEE Transactions on Control Systems Technology, vol. 12, no. 5, pp. 683-693, 2004.

[8] J. van Helvoirt and B. de Jager, "Dynamic model including piping acoustics of a centrifugal compression system," Journal of Sound and Vibration, vol. 302, no. 1-2, pp. 361-378, 2007.

[9] W. C. Oakes, P. B. Lawless, J. R. Fagan, and F. Sanford, "Highspeed centrifugal compressor surge initiation characterization," Journal of Propulsion and Power, vol. 18, no. 5, pp. 10121018, 2002.

[10] N. Brown, High speed compressor facility-electromechanical design, M.S. thesis, Department of Mechanical and Aerospace Engineering, University of Virginia, Charlottesville, Va, USA, 2005.

[11] B. de Jager, "Rotating stall and surge control: a survey," in Proceedings of the 34th Conference on Decisions and Controls, New Orleans, La, USA, December 1995.

[12] G. L. Arnulfi, P. Giannattasio, C. Giusto, A. F. Massardo, D. Micheli, and P. Pinamonti, "Multistage centrifugal compressor surge analysis: part 1-experimental investigation," Journal of Turbomachinery, vol. 121, no. 2, pp. 305-311, 1999.

[13] J. Sorokes, "Aerodynamically induced forces working on centrifugal compressors and resulting vibration characteristics of rotors," in Proceedings of the Turbomachinery Symposium, Houston, Tex, USA, September 2008.

[14] D. A. Fink, N. A. Cumpsty, and E. M. Greitzer, "Surge dynamics in a free spool centrifugal compressor system," Journal of Turbomachinery, vol. 114, no. 2, pp. 321-332, 1992.

[15] F. Willems, Modeling and bounded feedback stabilization of a centrifugal compressor surge, Ph.D. thesis, Department of Mechanical Engineering, Eindhoven University of Technology, Eindhoven, The Netherlands, 2000. 

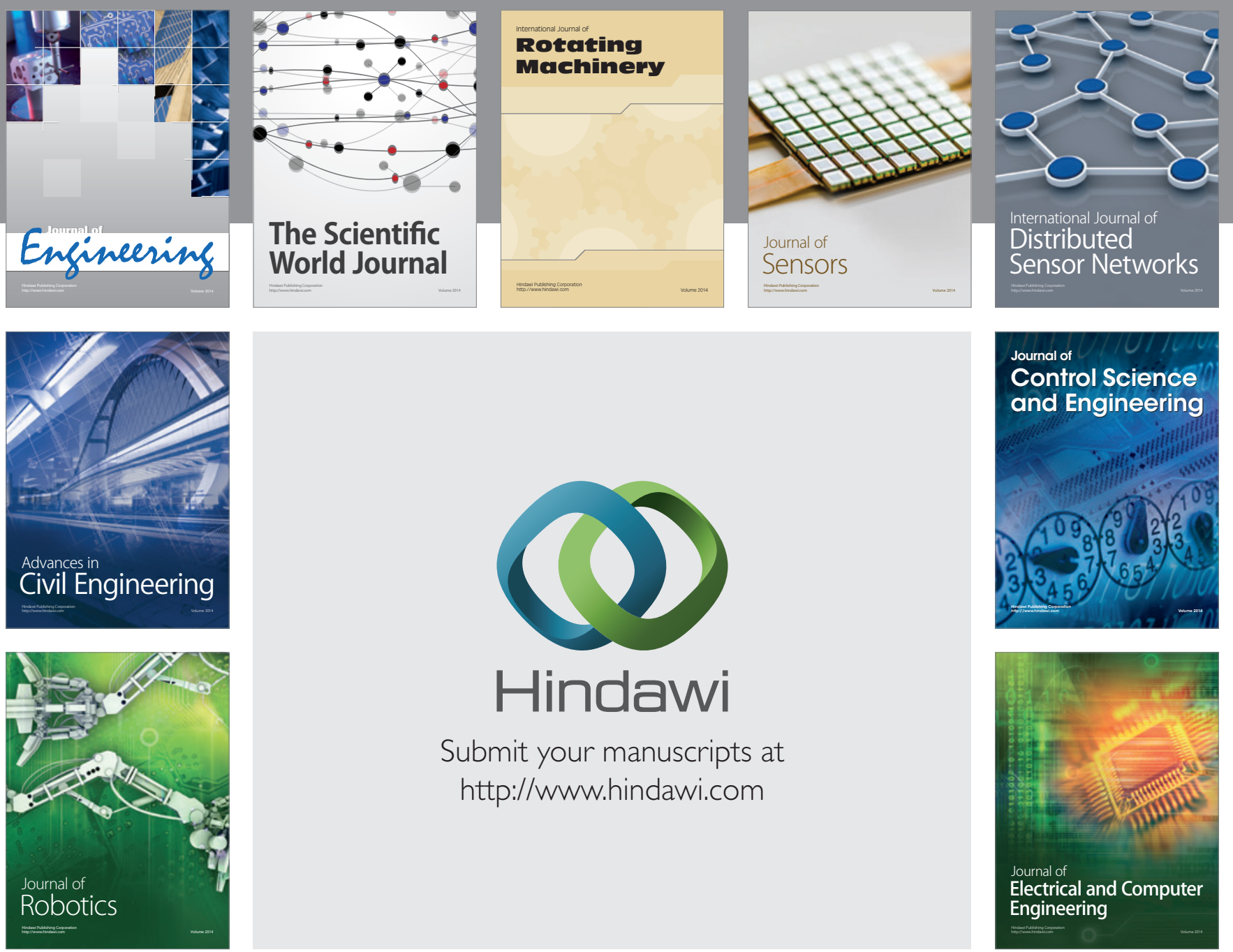

Submit your manuscripts at

http://www.hindawi.com
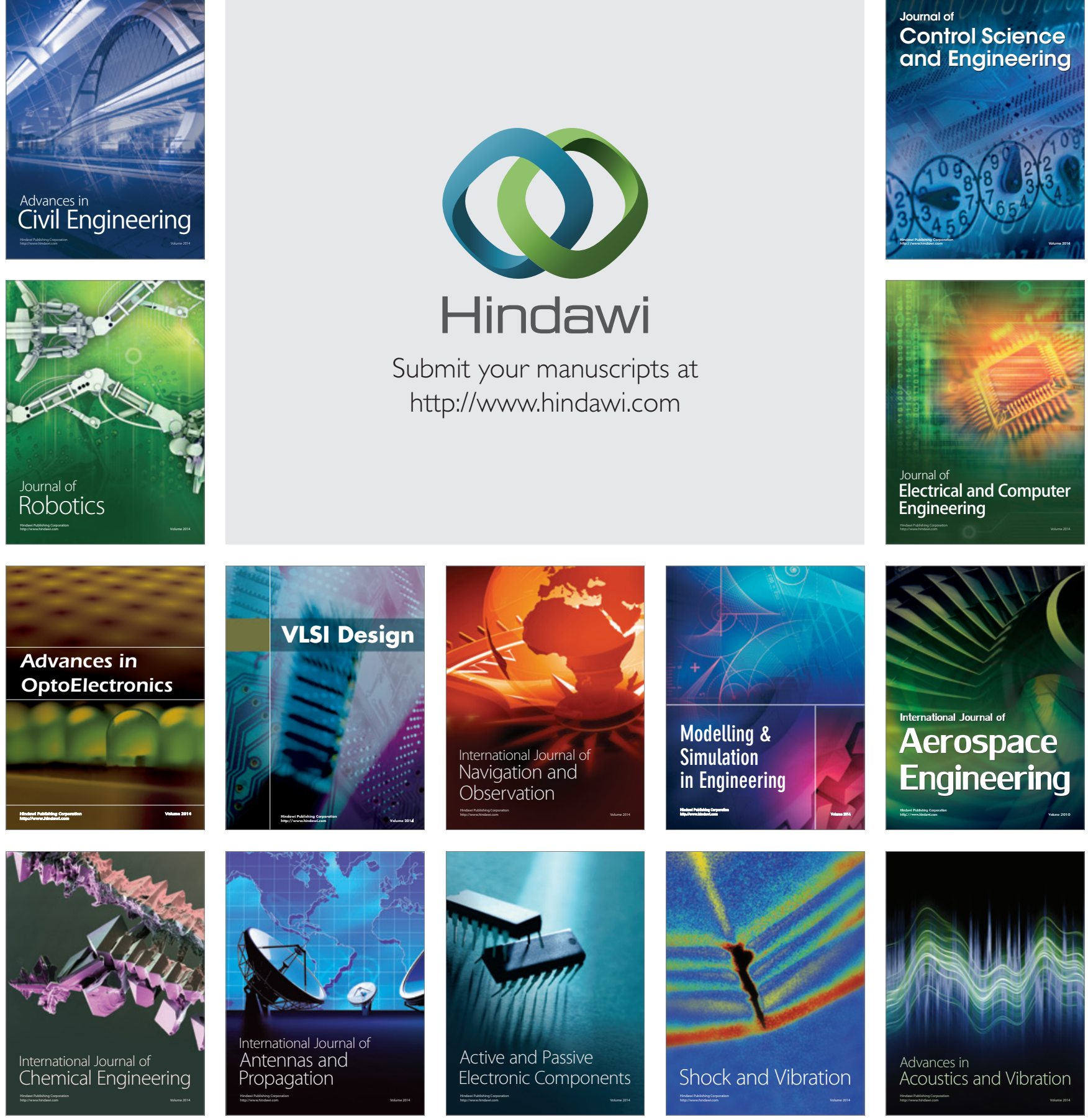